\title{
SURVEILLANCE FOR WEEVILS AND COBWEB SPIDERS AT HIGH RISK SITES AROUND CHRISTCHURCH, NEW ZEALAND
}

\author{
M.R. MCNEILL, C.J. VINK and C.B. PHILLIPS \\ Biosecurity Group, AgResearch, Lincoln, Private Bag 4749, Christchurch 8140, \\ New Zealand
}

Corresponding author: mark.mcneill@agresearch.co.nz

\begin{abstract}
Most arthropod traps available for biosecurity surveillance are either generic and incur problems with large bycatches, or are targeted at one or a few species and have limited application. Traps designed to be of intermediate specificity were tested at three high risk sites in Christchurch. Traps with and without attractants targeting weevils (Curculionidae), and two trap types targeting cobweb spiders (Theridiidae) were evaluated. The weevil traps captured nine weevil species from six genera, including the first detection of Sitona lepidus in the South Island. Significantly more weevils were captured in the traps with attractants. The spider traps captured spiders in the families Theridiidae, Linyphiidae and Agelenidae, including the first detection of Nesticodes rufipes (Theridiidae) in the South Island. For all traps, bycatches were small and readily processed, and included a cricket, Gryllodes sigillatus, that is not established in New Zealand. Traps of intermediate specificity have potential for operational use in high risk site surveillance. Keywords: biosecurity, early detection, high risk site, trapping, invasive alien species, semiochemicals, cone trap, Curculionidae, Theridiidae.
\end{abstract}

\section{INTRODUCTION}

Biosecurity surveillance is "the collection, collation, analysis, interpretation and timely dissemination of information on the presence, distribution or prevalence of risk organisms and the plants or animals that they affect" (MAF Biosecurity New Zealand 2007, 2008). This paper addresses the aspect of surveillance that concerns the detection of pests sufficiently early during their invasion into a new region to enable effective containment and eradication (i.e. early detection). As discussed by Kean et al. (2008), most New Zealand incursions of pests on plants are passively detected by the public before being reported to MAFBNZ (Wilson et al. 2004). Such detections often occur after the pest has already become widely distributed and abundant, thus reducing opportunities for effective management (Wilson et al. 2004). However, there are some examples of active surveillance programmes in New Zealand that target a wide range of taxa (e.g. high risk site surveys, crop surveillance) and a few programmes targeting specific taxa in specific places, such as invasive ants at seaports, and targeted trapping networks for gypsy moth and fruit flies (Kean et al. 2008; Martin et al. 2008).

Both general and specific surveillance programmes have limitations in their implementation. Targeted surveillance is often limited to those species for which effective attractants such as pheromones have been developed and such compounds are generally specific to just one or a few species (e.g. Cowley 1990). Taxa-specific surveillance can be labour-intensive and costly to maintain; for example, New Zealand's fruit fly surveillance programme has been running since the mid 1970s (Somerfield 1989) at a cost of around $\$ 1$ million per annum, a quarter of the total surveillance and response budget (Pearson 2002). The cost to implement sufficiently sensitive surveillance systems for other high 
risk pests would be of a similar magnitude (Ganev \& Braithwaite 2003; Stephenson et al. 2003). Such expense precludes implementation of active surveillance programmes for most high risk species in New Zealand. Conversely, general surveillance programmes are hampered by bycatch (e.g. Thomas 2003), which often results in major time lags between the collection of risk organisms and their identification. There are also technical difficulties (e.g. Teulon \& Scott 2006; Martin et al. 2008) and expenses associated with sorting biosecurity risk organisms from large bycatches. Clearly there is a requirement to consider the optimum balance between competing factors such as species specificity, detection efficacy, the need to implement surveillance for a wide range of high risk organisms, the challenge of dealing with bycatches, and economic costs.

The present research evaluated whether traps that could be expected to attract a range of species within a family, would incur significant costs in terms of the need to sort bycatches when they were deployed at high risk sites such as seaports and airports. It was postulated that some high risk sites would not support high population densities of many organisms due to the relative absence of vegetation, thus bycatches were likely to be modest. If true, this would suggest it may be possible to develop and implement surveillance programmes for a broad diversity of risk species at high risk sites for relatively lower cost. This idea was tested using two types of traps, one for weevils (Curculionidae) and another for cobweb spiders (Theridiidae). The work was also used as an opportunity to evaluate the performance of a blend of compounds expected to be attractive to Curculionidae.

\section{METHODS}

The study sites were Christchurch International Airport $\left(43^{\circ} 29.2^{\prime} \mathrm{S}, 172^{\circ} 32.7^{\prime} \mathrm{E}\right)$, Lyttelton Seaport $\left(43^{\circ} 36.3^{\prime} \mathrm{S}, 172^{\circ} 43.2^{\prime} \mathrm{E}\right)$ and a container devanning site in Hillsborough

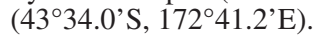

\section{Traps targeting Curculionidae}

A commercial boll weevil trap (Pherocon ${ }^{\circledR}$ Boll weevil traps, Trece Inc., USA) was modified by adding two entry portals to its base, drilling a $5 \mathrm{~cm}$ diameter hole in the top of the base, and painting the base yellow (Plasti-kote super enamel, T-29 School Bus Yellow).

A subset of the curculionid traps was baited with a plant extract, 1-octen-3-ol, and a combination of three insect semiochemicals: 4-methyl-3,5-heptanedione; 3-hydroxy4-methyl-5-heptanone; and 4-methyl-3,5-octanedione (Oeschem, UK). 4-methyl-3,5heptanedione is the aggregation pheromone for S. lineatus L. (Blight et al. 1984), while the latter two compounds are derivatives of the $S$. lineatus pheromone. Research elsewhere has shown that several species of Sitona and Hypera are attracted to 4-methyl3,5-heptanedione (Tóth et al. 1998; Quinn et al. 1999; Hardwick et al. 2004). Thirty $\mu$ l of each chemical was added to separate $0.5 \mathrm{ml}$ plastic vials and all four vials sealed in a polyethylene bag ( $210 \mu \mathrm{m}$ gauge), which was secured to the base section of the trap with wire. The removable top assembly was then fitted to the base.

Curculionid traps were secured to the ground either by pegging with wire pins, fixing them to fences, or by mounting them on wooden bases. They were placed at least $10 \mathrm{~m}$ apart and checked every 2-4 weeks, at which time the attractants were also replaced. Where possible, traps with and without attractants were paired, with members of each pair situated at least $10 \mathrm{~m}$ apart.

Eight curculionid traps, all containing chemical attractant, were placed at Christchurch Airport on 28 November 2005, with the number increased to 11 traps on 14 February 2006. All traps were removed for the winter on 3 May 2006. On 15 September 2006, 10 curculionid traps with attractant and eight without attractant were placed at the airport, and these were removed on 2 April 2007. The traps were situated around the perimeter of the airfield and in warehouses that receive international cargo. From 28 November 2005 to 27 March 2006, curculionid traps, all containing attractant, were deployed at Lyttelton Seaport (three traps) and the container devanning site (Hillsborough) (three traps). For the 2006-07 season, six traps with attractant and three without were deployed from 15 September 2006 until 17 April 2007 at both sites. 


\section{Traps targeting Theridiidae}

Two traps intended to target Theridiidae were assessed. One had been used to capture Latrodectus hasseltii Thorell in Japan (Kamimura et al. 1999) and the other to trap L. katipo Powell in New Zealand (Lettink \& Patrick 2006). Both provide shelter from rain and wind, and capture heat from the sun, which appear to be important to Latrodectus web site selection (C.J. Vink, pers. obs.). The traps were also expected to be attractive to other spiders that build webs in small spaces, such as linyphiids.

Six of each theridiid trap type were trialled at Lyttelton, three of each type at the Hillsborough devanning site, and one of each type at Christchurch International Airport. At each site, pairs comprising different trap types were placed approximately $1 \mathrm{~m}$ apart, and pairs of traps were situated at least $10 \mathrm{~m}$ apart. The three pairs of traps at the devanning site were placed up to $10 \mathrm{~m}$ from MAF inspection pads and container devanning sites. Each trap was secured by placing a brick on it.

\section{Arthropod identifications}

Where possible, all weevils and spiders were identified to species. Other arthropods were generally classified to order unless there was a need to identify them more accurately.

\section{Statistical analysis}

For weevils caught at Christchurch Airport from 15 September 2006 to 2 April 2007, the number caught per trap was analysed using a generalised linear model assuming a negative binomial distribution and a log link function. Terms in the model were block (position of traps around the airport), treatment (pheromone or control), date (when catch was counted) and the block by treatment interaction, fitted in that order with the significance of the treatment terms assessed using the ratio of the mean deviances for treatment and residual.

\section{Curculionid traps}

\section{RESULTS}

In the 2005-06 season, the Christchurch Airport traps were checked eight times and 30 adult weevils (mean 1.6 per trap) were recovered. The number of weevils collected was fairly consistent through time with a maximum of 11 weevils recovered from eight traps on 23 January 2006, including the first detection of Sitona lepidus Gyllenhal in the South Island (Phillips et al. 2007). The Lyttelton seaport and devanning site traps were checked six times and no weevils were recovered.

In the 2006-07 season, the Christchurch Airport traps were checked eight times and 109 adult weevils were recovered (mean ca 6 per trap). All but six of these weevils were recovered during the last four sampling occasions, which commenced on 9 January 2007. Overall, 73 weevils (mean 7/trap) were caught in traps with attractant, which was significantly more than the 36 weevils (mean 4/trap) caught in traps without attractant $(\mathrm{P}=0.046)$. Traps with and without attractants situated in a cargo handing warehouse caught 32 and six Otiorhynchus ovatus (L.), respectively, between 9 January and 2 April 2007. Only two weevils, Irenimus aequalis (Broun) and Sitona discoideus Gyllenhal, were recovered from Lyttelton seaport, while none were captured at the devanning site.

Across all sites, weevils collected were Exapion ulicis (Förster), I. aequalis, Listronotus bonariensis (Kuschel), Otiorhynchus sulcatus (Fabricius), O. ovatus, O. rugosostriatus (Goeze), S. lepidus, S. discoideus and Steriphus diversipes lineata (Pascoe). These include both winged and apterous species, and all species except I. aequalis and $S$. diversipes are adventive.

\section{Bycatch in the curculionid traps}

At Christchurch Airport in 2005-06, 133 non-weevil insects were also recovered. This bycatch included Lepidoptera (36 specimens, 27\%), Diptera (33, 25\%), Hemiptera $(28,21 \%)$, Coleoptera other than Curculionidae $(18,14 \%)$, Hymenoptera $(14,11 \%)$ and Neuroptera $(5,4 \%)$. Eighteen spiders were also collected.

At Christchurch Airport in 2006-07, 246 non-weevil insects were also recovered. This bycatch included Lepidoptera $(27,11 \%)$, Diptera $(62,25 \%)$, Hemiptera $(13,5 \%)$, 
Coleoptera other than Curculionidae (54, 22\%), Hymenoptera $(34,14 \%)$ and Neuroptera $(51,21 \%)$. Fifty-five spiders were also collected. Similar numbers of non-weevil insects were caught in the traps with attractant (120 specimens) and without (126 specimens).

\section{Theridiid traps}

Local spider species (e.g. Theridiidae, Linyphiidae, Agelenidae) were found in all spider traps at all sites, and a trap at the LPC Hillsborough depot captured a single female Nesticodes rufipes (Lucas) (Theridiidae). This is the first detection of this cosmopolitan, synanthropic spider in the South Island.

\section{Bycatch in the theridiid traps}

An unexpected discovery in a spider trap at the devanning site at Hillsborough was a single specimen of Gryllodes sigillatus (Walker) (Indian house cricket) in January 2007, which is not present in New Zealand, though it is a well known invader overseas. Biosecurity authorities were informed and a minor incursion response ensued. No other organisms occurred as bycatch.

\section{DISCUSSION}

High risk sites, such as large airports and seaports, are intensively built environments where vegetation is often sparse and populations of most arthropods may occur at low densities. This study provided some initial support for the possibility that such environments could be exploited to benefit surveillance trapping by minimising costs and difficulties associated with processing large bycatches. The results also indicated that it should be feasible to develop and use traps of intermediate specificity (e.g. targeted at families rather than at one or a few species) to increase the range of species included for surveillance at such sites. Both the curculionid and theridiid traps made detections within their targeted families that were relevant to biosecurity (i.e. S. lepidus and $N$. rufipes, respectively) and in neither case were the bycatches large enough to impede recovery and identification of the organisms of interest. That the semiochemicals used in the curculionid traps were attractive to Curculionidae rather than other groups was supported by the recovery of nearly equal numbers of non-curculionid arthropods in traps with and without attractants.

In future, it would be useful to conduct additional work at high risk sites to directly compare the bycatch from sampling methods of intermediate specificity, such as those used in the present study, with more generic trapping approaches, such as suction traps and sticky traps. This would help to identify the degree of trap specificity that would optimise benefits and minimise costs when conducting surveillance at high risk sites. A difficulty with some generic traps is that specimens can be damaged, which makes identification problematic (e.g. Teulon \& Scott 2006).

Associated with the relative absence of vegetation from many high risk sites is the possibility that there are relatively few natural host- or habitat-finding cues for arthropods to respond to. This suggests that artificial attractants might be comparatively effective in intensively built environments because they are not competing with other more natural cues. Preliminary evidence of this has been obtained from two sources related to the present study. First, weevil capture rates at Christchurch Airport tended to be higher in curculionid traps that were situated relatively distant from vegetation rather than close to it. Second, even though many of the weevil species that were caught at Christchurch Airport during this study also occur at relatively high densities in pasture (e.g. I. aequalis, L. bonariensis, S. lepidus, and Steriphus diversipes lineata), tests of the curculionid traps in Canterbury and Nelson pastures have generally failed to capture them (M.R. McNeill \& C.B. Phillips, unpubl. data).

The high capture rates of flightless weevils such as Otiorhynchus spp. inside cargo warehouses that were distant from vegetation was unexpected. It is uncertain if these weevils arrived with cargo or were attracted inside the buildings by lights. It is notable that all of the non-native weevil genera collected in the traps contain numerous additional species (e.g. Morris 1997, Velázquez de Castro et al. 2007) that could be harmful if they reached New Zealand (e.g. Phillips \& Barratt 2004). Thus the attractant curculionid traps appear to have value for border surveillance, assuming that an effective response to such detections would be possible. 
Several spider species including Nesticodes rufipes, a species previously not recorded in Christchurch, were observed in both passive spider traps at high risk sites. These traps rely on spiders encountering them and spiders will wander in search of suitable microhabitats (e.g. Hodge 1987). However, if the traps were combined with an attractant they would probably be more effective. Spiders have been found on a number of decomposing organic materials and they may forage on these decaying resources because of the high density of prey associated with them (Hodge \& Vink 2007). By including semiochemicals that mimicked decomposing organic material, it may be possible to attract spiders to the traps.

\section{ACKNOWLEDGEMENTS}

The authors thank Sam Brown for identification of some of the Curculionidae, Chikako van Koten for statistical analysis and Glen Dawson for the supply of the semiochemicals used in this study. Thanks also to staff from Ministry of Agriculture and Forestry Biosecurity New Zealand, Lyttelton Port Company, Christchurch International Airport Ltd., Raytheon, CargoPort, Canterbury Aero Club and the Airport Fire Service for their cooperation and assistance in conducting this study. This work was funded by New Zealand's Foundation for Research, Science and Technology through Contract CO2X0501, the Better Border Biosecurity (B3) programme (www.b3nz.org).

\section{REFERENCES}

Blight MM, Pickett JA, Smith MC, Wadhams LJ 1984. An aggregation pheromone of Sitona lineatus: Identification and initial field studies. Naturwissenschaften 71: 480-481.

Cowley JM 1990. A new system of fruit fly surveillance trapping in New Zealand. New Zealand Entomologist 13: 81-84.

Ganev S, Braithwaite M 2003. Resource requirements for national active surveillance programmes of high impact exotic pests in New Zealand. New Zealand Plant Protection 56: 10-15.

Hardwick S, Proffitt JR, McNeill MR, Harens B, Goldson SL 2004. Cross receptivity of Sitona lepidus to Sitona lineatus and Sitophilus species (Coleoptera: Curculionidae) aggregation pheromones. Proceedings of the 8th Australasian Conference on Grassland Invertebrate Ecology: 118-125.

Hodge MA 1987. Macrohabitat selection by the orb weaving spider, Micrathena gracilis. Psyche 94: 347-362.

Hodge S, Vink CJ 2007. Do epigeal spiders show a spatial association with patches of rotting fruit? Newsletter of the British Arachnological Society 109: 7-10.

Kamimura K, Yoshida M, Nishio Y, Matsuse IT, Shimano S, Shirai Y 1999. Overwintering of Latrodectus hasseltii in shelter traps in Osaka prefecture. Medical Entomology and Zoology 50: 137-140.

Kean JM, Phillips CB, McNeill MR 2008. Surveillance for early detection: lottery or investment? In: Froud KJ, Popay AI, Zydenbos SM ed. Surveillance for biosecurity: pre-border to pest management. New Zealand Plant Protection Society Incorporated, Hastings, New Zealand. Pp. 11-17.

Lettink M, Patrick BH 2006. Use of artificial cover objects for detecting red katipo, Latrodectus katipo Powell (Araneae: Theridiidae). New Zealand Entomologist 29: 99-102.

Martin NA, Wright PJ, Fletcher JD 2008. Unwanted in New Zealand: diseases and pests of crops. In: Froud KJ, Popay AI, Zydenbos SM ed. Surveillance for biosecurity: pre-border to pest management. New Zealand Plant Protection Society Incorporated, Hastings, New Zealand. Pp. 81-87.

MAF Biosecurity New Zealand 2007. MAF Biosecurity New Zealand biosecurity surveillance strategy - Review of the current state of the biosecurity surveillance system. Ministry of Agriculture and Forestry, Wellington, New Zealand. 40 p. 
MAF Biosecurity New Zealand 2008. Biosecurity Surveillance Strategy 2020 (draft). Ministry of Agriculture and Forestry, Wellington, New Zealand. 51 p. http://www. biosecurity.govt.nz/surveillancestrategy (accessed 29 May 2009).

Morris, M.G. 1997. Broad nosed weevils, Coleoptera: Curculionidae (Entiminae). Handbook for the identification of British insects 5 (17a). Royal Entomological Society, London. $106 \mathrm{p}$.

Quinn MA, Bezdicek DF, Smart LE, Martin J 1999. An aggregation pheromone system for monitoring pea leaf weevil (Coleoptera: Curculionidae) in the Pacific Northwest. Journal of the Kansas Entomological Society 72: 315-321.

Pearson AB 2002. An independent review of New Zealand's biosecurity surveillance systems. http://www.biosecurity.govt.nz/pests-diseases/surveillance-review/index. htm (accessed 29 May 2009).

Phillips CB, Barratt BIP 2004. A guide to assist detection of newly arrived Sitona species (Coleoptera: Curculionidae) in New Zealand and Australia. In: Winder LM, Goldson SL ed. Proceedings of $8^{\text {th }}$ Australasian Conference on Grassland Invertebrate Ecology. Pp. 22-33.

Phillips CB, McNeill MR, Hardwick S, Vink CJ, Kean JM, Bewsell D, Ferguson CM, Winder LM, Iline II, Barron MC, Stuart B 2007. Clover root weevil in the South Island: detection, response and current distribution. New Zealand Plant Protection 60: 209-216.

Somerfield KG 1989. Establishment of fruit fly surveillance trapping in New Zealand. New Zealand Entomologist 12: 79-81.

Stephenson BP, Gill GSC, Randall JL, Wilson JA 2003. Biosecurity approaches to surveillance and response for new plant pest species. New Zealand Plant Protection 56: 5-9.

Teulon DAJ, Scott IAW 2006. The use of suction traps for detection of unwanted invasive insects and other invertebrates. New Zealand Plant Protection 59: 125-131.

Thomas DB 2003. Nontarget insects captured in fruit fly (Diptera: Tephritidae) surveillance traps. Journal of Economic Entomology 96: 1732-1737.

Tóth M, Smart LE, Szarukón I, Imrei Z 1998. Preliminary observations on species specificity of Sitona lineatus (L.) pheromone traps in Hungary (Coleoptera: Curculionidae). Acta Phytopathologica et Entomologica Hungarica 33: 349-356.

Velázquez de Castro AJ, Alonso-Zarazaga MÁ, Outerelo R 2007. Systematics of Sitonini (Coleoptera: Curculionidae: Entiminae), with a hypothesis on the evolution of feeding habits. Systematic Entomology 32: 312-331.

Wilson JA, Stephenson BP, Gill GSC, Randall JL, Vieglais CMC 2004. Principles of response to detections of new plant pest species and the effectiveness of surveillance. New Zealand Plant Protection 57: 156-160. 